\title{
Reseña
}

\section{Alta Suciedad. La Ciudad Analítica}

\author{
Eugenia Destefanis*
}

Centro de Investigación y Estudios Clínicos, Argentina

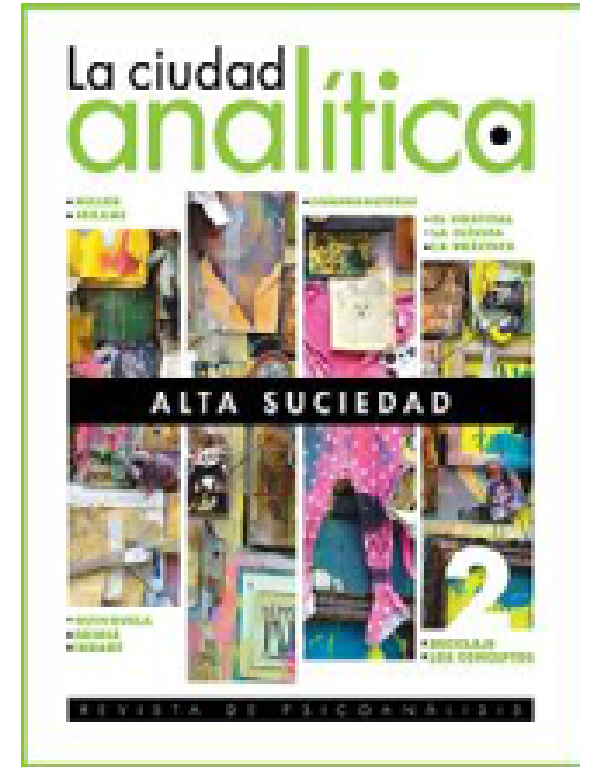

Alta Suciedad (2019) es el nombre que lleva el segundo número de la Revista del Instituto Clínico de Buenos Aires (ICdeBA), La ciudad analítica. Revista que nos invita a "descubrir la política lacaniana del objeto a" (p. 9), como nos lo dice en la nota editorial, su directora de redacción, Daniela Fernández. En esta oportunidad, nos encontramos con más de treinta artículos que bordean uno de los objetos lacanianos más paradójicos: el objeto anal.

En Las ruinas del objeto, texto que le da inicio a este número, Jacques- Alain Miller (2019) transmite una precisión que nos orientará en todo el recorrido: "fuera-de-significado, el objeto anal es aquel del que tenemos que deshacernos y que se acumula a pesar de haberlo abandonado" (p.18). Objeto del cual jamás podremos librarnos ya
Índice $\mathrm{N}^{\circ}$ 2: Alta suciedad

Jacques- Alain Miller

Los conceptos

La clínica

El hospital

La práctica

Miniaturas

Las cartas

Misceláneas: Foucault, Marx, Huxley

Las letras: Beckett, Swift

City-tour: Quinquela, McQueen, Beckett, Kuczynski

La entrevista

Dossier: Mundo Inmudo

Bonus track: Comprometerse | Gérard Wajcman

Epílogo que "aquello que más rechazas, es lo que tú eres y siempre fuiste” (p.8), cita Daniela Fernández retomando a Lacan.

El objeto anida en la civilización. Desde siempre, el hombre tuvo que vérselas con los objetos que lo rodean. Objetos de consumo, de adoración, de colección, así como también de desecho. El hombre acumula diccionarios, bibliotecas, conocimiento, ciencia y su propia mugre, pero no sabe bien qué hacer con sus desechos, plantea el Dossier Mundo Inmundo citando a Lacan. Los escritos de dicho Dossier, abordan el objeto anal en lo social y las distintas maneras de hacer con los restos. Escoria , da cuenta del objeto en su cara más cruel, como puro desecho, y su articulación con el nazismo y el racismo. Belleza cartonera, es un ejemplo de un saber hacer

* eugeniadestefanis@gmail.com 
con los desechos, un ejemplo de cuando el resto se vuelve causa y efecto de deseo, como lo muestra el trabajo que lleva a cabo la cooperativa editorial que fabrica libros de manera artesanal con cartón recolectado por cartoneros. Reciclaje, por su parte, se ocupa del mandato imperante del ideal capitalista que empuja a la evacuación sin resto. Búsqueda que desconoce un imposible: hay algo de lo que no podremos deshacernos jamás.

Sobre esta paradoja del objeto en la civilización, Guy Briole dice: "el mundo está fundado sobre la Cloacine, la diosa etrusca, que es al mismo tiempo la diosa de la limpieza y de la cloaca" (p.63). En una imperdible entrevista que le realiza La ciudad analítica, nos enseña de su práctica en el hospital, de su saber hacer con los desechos, de lo que implica el psicoanálisis para él, de cómo fue su encuentro con Lacan, de las guerras y el odio. "La guerra ensucia todo" (p. 61). Y continúa: "en dicha guerra de las pulsiones hay que poder civilizar el objeto anal, porque si nos dejamos atrapar por este objeto, hay algo que irá hacia lo peor. Hay siempre algo por destruir ¡el desecho del desecho!” (p.61)

La ciudad analitica no habla sola, sale a la ciudad, ese es su escenario. Como lo expresa Ariel Chiodi en el Epílogo : "La ciudad analítica es nuestro discurso en la ciudad" (p.153). Dialoga, conversa con otros discursos, se deja interpelar por acontecimientos que interpreta. A medida que la recorremos nos encontramos con distintos tratamientos del objeto. Pasamos por el arte, la literatura, el teatro, los fenómenos de la época. La clínica, El hospital, Las prácticas y Miniaturas, abordan el objeto anal puesto en acto. La praxis analítica, los lugares donde ésta se lleva a cabo, contando con la rigurosidad conceptual y el esfuerzo de escritura para la transmisión de casos, que nos enseñan muy bien acerca del objeto anal en la dirección de la cura, su operatividad, su alcance clínico y su relación con el deseo del analista. Este último exhaustivamente trabajado en la sección Conceptos : el deseo del analista está marcado por una impureza, el cual lo anima y da sustento a la manera de ejercer la función.

Asimismo, dialoga con pensadores de otras disciplinas: Marx, Foucault, Huxley. Y, por supuesto, no desconoce a Freud en todo esto, nos da el gusto de leerlo a partir de una de las perlas de su obra: Las Cartas .
En City Tour sale al encuentro de Quinquela Martin, Beckett, Mc Queen y Kuczynski. Cada uno de ellos, con su arte, portando un saber hacer con el objeto anal. Allí se puede localizar un precioso recorte a partir de la obra de Beckett Los días felices: "cada uno, e incluso el amor, esconde bajo sus ropajes el objeto desecho" (p. 123).

En la vertiente de acumulación y adoración del objeto, la entrevista a un coleccionista de arte: Anibal Jozami quien da cuenta de la experiencia de ser "un buscador de belleza", modo en que nombra el ser coleccionista. Mientras que el Bonus Track es una joya. Un imperdible texto de Gerard Wajcman que nos dice: "el psicoanalista, toma partido, elige, se compromete” (p. 150).

La posición del analista frente a los restos, frente a los desechos, atraviesa el número. Cada uno de los escritos de Alta Suciedad da cuenta de la importancia del desecho para el psicoanálisis. “QQué hacemos los psicoanalistas con los restos?”, se pregunta Ariel Chiodi en el Epílogo . Esto resuena con el apartado Las letras, donde nos encontramos con el glotón de Joyce y el anoréxico de Beckett, "el resto tiene todo su valor en psicoanálisis y Lacan se ubica junto a Beckett en el tacho de basura donde saben hacer algo con él" (p. 107). En consonancia, Reciclaje plantea: "lo que hace el ser hablante con su porquería nos incumbe, si de psicoanálisis se trata. El analista se ubica en sintonía con la posición del cartonero, en semejanza con estos recolectores que surcan la ciudad agitando los cubos de basura, esperando el hallazgo" (p. 147).

De este modo, La ciudad analítica nos muestra el alcance y el estatuto del objeto anal en la praxis y clínica lacaniana. Nos ubica en el entusiasmo y el desafío del psicoanalista por aproximar el deseo a lo más inmundo de cada parlêtre; dando cuenta que desde sus inicios el psicoanálisis se ocupó de los desechos de la vida psíquica, como nominaba Freud a los lapsus, sueños, síntomas y actos fallidos. Nos enseña de La salvación por los desechos, como lo define Miller sirviéndose de la fórmula del surrealismo.

La ciudad analítica es una belleza en sí misma, es un precioso tratamiento de uno de los objetos más desagradables. Su lectura es un deleite de cultura, de actualidad y de rigurosidad conceptual. ¡A no perdérsela! Alta suciedad es un objeto del que no querrán desprenderse.

\section{Referencias}

Alta suciedad (14 de mayo de 2019). La ciudad analítica. Revista de Psicoanálisis. ICdeBA. (2). 